\title{
A Gender Analysis of Attitudes to Students Residences in Nigeria
}

\author{
Dolapo Amole \\ Department of Architecture, \\ Obafemi Awolowo University, Ile-Ife, Nigeria \\ dolapoamole@yahoo.com
}

\begin{abstract}
This paper examines gender differences in responses to different aspects of students' housing in two identical single-sex halls of residence in a Nigerian university. A questionnaire survey was used to elicit data from 150 students about their attitudes towards their accommodation, the design, social densities, choices and preferences, use of facilities and coping strategies. Gender differences were found to be most significant with respect to the use of domestic facilities, social densities, and design issues. The paper confirms previous studies about gender differences, identifies directions for future research and discusses the implications for the design of students' residence halls.
\end{abstract}

Keywords: Students' housing; Gender; Crowding, Behavior, Halls of Residence, Attitudes.

eISSN 2514-751X @ 2017 The Authors. Published for AMER ABRA by e-International Publishing House, Ltd., UK.. This is an open access article under the CC BY-NC-ND license (http://creativecommons.org/licenses/by-ncnd/4.0/). Peer-review under responsibility of AMER (Association of Malaysian Environment-Behaviour Researchers), ABRA (Association of Behavioural Researchers on Asians) and cE-Bs (Centre for EnvironmentBehaviour Studies), Faculty of Architecture, Planning \& Surveying, Universiti Teknologi MARA, Malaysia.

https://doi.org/10.21834/aje-bs.v2i3.183 


\subsection{Introduction}

Researchers still continue to debate the nature of gender difference (Giddens, 2001:107). Those who attribute the difference between males and females to biology or nature think that certain biological aspects such as hormones and chromosomes are responsible for the innate differences between males and females. Others assert that gender identities are learnt through the processes of socialization. They claim that through the agents of socialization such as the family, the school and religious organizations, children learn and internalize the social norms which correspond to their sex. Still, others argue that gender is a social construct. In other words, gender is a social creation which lacks a fixed reference point or essence; it is not related to sex but only as the society defines it. Post-modern feminists, on the other hand, argue against totalitarian views of gender or feminism and think that the focus should be on the fragmented subclasses of each gender. In spite of these debates, what seems certain is that gender differences in behaviour exist and gender differences should still continue to be investigated. The more they are investigated, the more the results will illuminate these debates and consequently inform us of the roles which nature and social institutions play in the development of gender identities.

Differences between males and females have been examined in many studies in the built environment (Harrison et al, 1991; Lawton et al, 1996; Kwan, 2000;

Kakad, 2000; Shrestha, 2000 Pain, 2001;). For example, Lawton et al, (1996) examined gender differences in indoor way-finding while Mathews (1987) investigated the cognitive mapping abilities of males and females. Significant gender differences were found to be accurate in locating directions but not in the choice of routes. Gender differences in the context of housing have also been examined. Gifford (1997) noted that it is the social roles ascribed to males and females which have often been at the root of these differences. In one of the reviews, he reported that some researchers (Peatross and Hansell, 1992) found significant differences on how satisfied husbands and wives were with their apartments, and the most important space in this regard was the kitchen. This study found that as men increasingly enjoy cooking, similarities and differences in men's and women's preferences for kitchen designs become more important. Consequently, Gifford (1997:201) suggested that it is the social roles and the corresponding physical spaces in which these social roles are performed which account for the differences in gender responses, behaviours and experiences of spaces. It would be interesting to examine dwelling contexts in which young unmarried adults rather than married adults live and to see if there would be significant gender differences in attitudes towards such places as the kitchen.

Another author, Walden, et al (1981) examined gender differences in the privacy of the bedrooms. In a study of dormitory residents, they found that males and females responded differently to two-person and three-person room arrangements. Males who were assigned to two-person rooms increased their preferences for all other forms of privacy while women did not show changes in any preference for privacy. The authors concluded that this was not enough to say that females valued privacy less than males. They explained this finding 
with the coping mechanisms adopted by males and females in the study. The suggestion was that females appeared to enjoy the company of others more and when asked to live in higher density situations probably had a greater number of coping mechanisms; whereas the coping mechanisms of males were to adjust the values they placed on privacy and escape from the social context.

Gender differences in response to crowding have also been found. Gifford (1997: 149) in a review of some articles concluded that males and females react differently to high density in laboratory experiments. Specifically, he noted that males respond to high density more negatively than females in mood, attitudes towards others, social behaviour and are more hostile. Females seem to handle crowded situations better. The reasons given for this differences are related to socialization such as males being discouraged from showing emotion and so being less able to share stress. However in field studies, it appears that females report more crowding than males when assigned to two or three person per rooms. A reason given for this was that it appeared that males were able to cope by staying away from the room, which they could not do in laboratory settings and that the females spent more time with their roommates; a situation which was more involving and stressful. Gender differences in response to crowding is not only amongst adults but is exhibited by both sexes even from the age of nine (Aiello et al 1979). For example, Maxwell (2003) examined the role of spatial density on elementary school children and found that girls' academic achievement and boys' classroom behaviour were negatively affected by less space per student and spatial density conditions.

The influence of age and stage in the life cycle on the responses of males and females on the built environment cannot be ignored. The studies which examined gender differences in children and youths in the built environment attribute some of the reasons for these differences to parental or societal influences. For example, Mathews (1987) suggests that boys were able to draw broadly conceptualized and more detailed maps by the age of 11 because they had begun to enjoy more parental granted rights. However, because most of the articles reviewed by Gifford (1997: 201) were about adult males and females $\mathrm{He}$ inferred that it is the social roles ascribed to males and females rather than intrinsic gender differences which have often been the root of gender differences.

From the literature, it appears that studies of gender differences in housing and residential environments have focused more on spatial behaviour issues such as spatial density, crowding, territorial behaviour and privacy and less on physical and affective issues such as specific spaces, facilities, attitudes and preferences. To fill this gap, this study investigated gender differences in students' responses to their housing. It identified whether there were gender differences in response to various dimensions of the students housing. It also identified where these differences were most significant as well as what could be inferred from the results with respect to the current debates on gender difference. The dimensions along which students in this context evaluated their residences from the literature (Amole, 1999, Amole, 2009) were selected. These were the bedroom, social density, privacy, coping mechanisms, overall design (image), physical facilities and the 
different dwelling levels of the halls of residence. It examined these differences and explanations were proffered.

\subsection{Methodology}

This paper presents the results of part of a larger study which evaluated some students' residences in Nigeria. For this paper, the context of the study was the

University of llorin in Nigeria. The setting was the male and female halls of residences. These halls were designed in exactly the same way. Hence the males and females students experienced the same environment. This presented the researcher the opportunity to rule out other possible physical influences on the responses of the students. The halls of residence were designed in the form of one-storey buildings with a courtyard within each block. Each block had twelve bedrooms on a floor, with sanitary, kitchen and laundry facilities at the end of the rectangular forms. There were 3 types of bedrooms; the 4-bed, the 6-bed and the 8-bed types. The 4-bed and the 6-bed rooms were on the ground floor while the 8-bed rooms were on the first floor (Fig.1, Fig. 2 and Fig.3). There was only one dimension in which the halls of residence of the males and females were not similar. This was the number of persons residing in the halls. Although the official numbers of person assigned was an average of 7 per room for the males and 5 per room for the females, the number of persons who slept in the room (as reported by the respondents) was an average of 15 persons per room for the males and 9 for the females. This context could be described as a high-density situation not by the design but because the students reported that more than double the official number slept in the bedroom daily. In actual fact, the situation for the males was probably more than a doubling of the intended design density. This is because, the numbers of persons officially assigned to the bedrooms should have been the same for both males and females since the design of the facilities were the same. Hence the situation appeared as a doubling of the proposed social density for the females and tripling for the males. Nevertheless this was an opportunity to analyze gender responses to crowding.

Separate dwellings that are built in exactly the same way for both males and females suggest gender neutral needs, responses and behaviours at least as far as dwelling is concerned. If differences emerge in responses to such dwellings, it may be that the buildings have not taken into account these differences and that there is indeed no gender neutrality in such a context.

About 15\% (150 in number) of the students accommodated in the halls of residence were selected for a questionnaire survey. The method of sampling was the stratified method. This method was used in order to ensure that a representative sample of students from different levels of study and different disciplines were represented. Only 144 questionnaires were returned and found useful. This was a very good response rate. Of these respondents, $51.8 \%$ were male and $48.2 \%$ were female. 


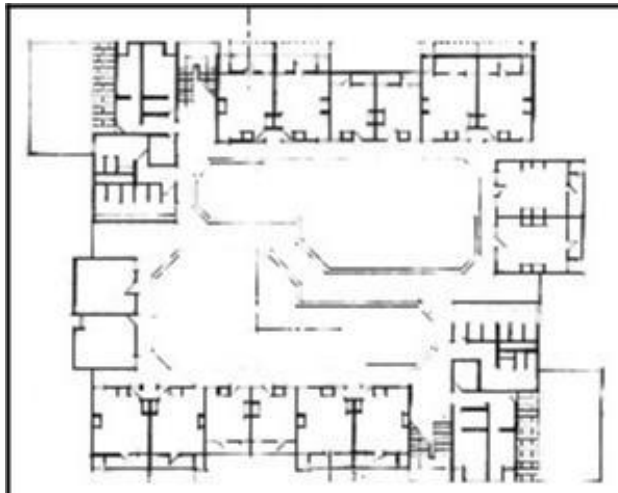

Figure 1: Ground floor plan of typical hall of residence

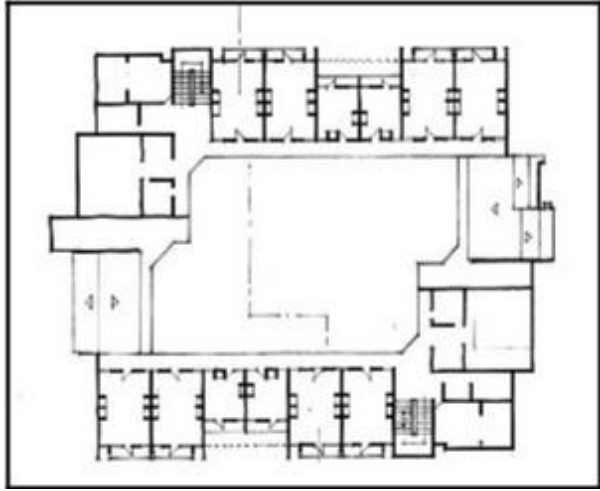

Figure 2: First floor plan of typical hall of residence

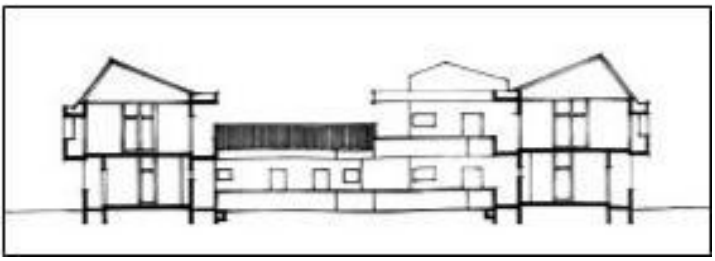

Figure 3: A Section through a typical hall of residence 
The instrument used for the survey was the self-administered questionnaire. It examined

(i) Attitudes towards the accommodation and its physical facilities; what was liked and disliked about the hall in general and the bedroom; rating of bedroom for different activities;, rating of comfort, overall design, furniture arrangement in bedroom and storage; attitude to kitchen.

(ii) Attitudes towards privacy and high social densities: attitudes to numbers of people in the hall and in the bedroom; privacy in the bedroom; feeling of freedom in the bedroom, number of persons sharing toilets and kitchen; satisfaction with social densities in the hall in general, at the level of the floor and in the bedroom.

(iii) Use of facilities: frequency of use of laundry, common room and kitchen; the other spaces used for these activities.

(iv) Preferences for different aspects of housing: who to share with; type of accommodation; where to study; where to live and numbers of persons to share kitchen with.

(v) factors influencing residential choice: such as the people who live there,the location of the hall, the maintenance of the hall, the number of the persons per room, the design and general appearance, the bathrooms and toilets, the rules and regulations, the accommodation fees, the variety of facilities in the hall, the location of the room on the floor, the floor level.

(vi) Coping strategies used: studying away from the room, staying away from the room, storing some personal items outside the room, rearranging the furniture provided in the room, decorating personal place in the room, generally demarcating personal space in the room, sleeping elsewhere outside the room, entertaining and meeting friends outside the room, and coming to the room only to sleep.

The main and important spaces in the halls of residence were selected as the reference for the study. This included the hall at a general level, the bedroom, and facilities such as kitchenettes, laundry, common room reading rooms and the design (image) of the hall. The responses to these questions were analyzed using cross tabulations and chi-square tests (specifically, Fischer's Exact test) to examine gender differences. This analysis indicated whether there was an association between gender and the various variables.

\subsection{Discussion}

\subsection{Attitudes towards university accommodation and facilities}

Responses about what the students liked or disliked about university accommodation and how satisfied they were with their accommodation were examined. There were no gender differences in their attitudes with the accommodation in general. However, when gender 
differences were examined at different hierarchical levels of the environment (or with more specific places), the results showed that there were differences in attitudes towards the hall $\left(\lambda^{2}=13.650 p \leq 0.028\right)$ and the bedroom $\left(\lambda^{2}=13.650 p \leq 0.023\right)$. Males and females varied significantly in what they disliked about the halls and the bedrooms. More males than females disliked more aspects of the hall and bedroom. It appeared that the hall and the bedroom raised more negative feelings for the males than for the females.

The study did not find gender differences with more specific aspects of the residences such as the rating of the bedroom as a place for various activities like sleeping, entertaining friends, relaxation and studying. In addition no gender differences were found in the rating of comfort in the bedroom and quality of sanitary facilities. However, males and females differed in their rating of the design of the hall $\left(\lambda^{2}=9.450 p \leq 0.0473\right)$ and how much they liked the furniture arrangement in the bedroom $\left(\lambda^{2}=10.349 p \leq 0.033\right)$. Both of these dimensions suggest that there are gender differences in artistic and design issues; a matter which has been supported in the literature by Keeley and Edney, (1983) but not supported by Stamps and Nasar, (1997) who found very high correlations between male and female preferences for architectural styles. This implies that more research needs to be conducted in this regard in order to explain the relationship between gender and design preferences.

\subsection{Housing preferences and factors affecting housing choice}

Preference for where to live (home, off-campus or on-campus accommodation) on the basis of gender was also examined. The results showed there were no gender differences in these preferences. In addition, there were no differences (between males and females) in preferences for where to study, type of accommodation, who to share with and social densities for sharing kitchen and sanitary facilities. However, there were significant differences in values placed on two factors in choosing where to live. These factors were the kinds of people who live in the place $\left(\lambda^{2}=19.745 p \leq 0.021\right)$ and the social densities of the bedroom $\left(\lambda^{2}=21.610 p \leq 0.008\right)$. More males ranked these factors higher than females. These findings suggest that gender differences in preferences in housing amongst young adults are more associated with psycho-social issues rather than the physical dimensions of housing.

\subsection{Use of facilities}

The most significant gender differences were found in the use of certain spaces in the halls of residences. These spaces were the kitchenette and the laundry spaces provided in the residences. Gender difference were found in how often they used the kitchenette $\left(\lambda^{2}=\right.$ $52.666 p \leq 0.000)$, where else the students cooked $\left(\lambda^{2}=15.079 p \leq 0.005\right)$, how often they used the laundry $\left(\lambda^{2}=22.301 p \leq 0.000\right)$ and where else they did their laundry $\left(\lambda^{2}=16.283\right.$ $p \leq 0.004)$. Specifically, the results showed that more females $(45.5 \%)$ than males $(6.1 \%)$ often used the kitchen and they (both males and females) cooked in very different places. More $(35.2 \%)$ of the females also used the laundry often/always than the males $(15.4 \%)$ and they both used a wide variety of other places for laundry. Gender differences were also 
found in the students' attitudes to the kitchenette provided ( $\left.\lambda^{2}=27.528 p \leq 0.000\right)$; more females found the kitchen more convenient than the males.

These results present an instructive picture of gender differences in spatial behaviour. The results suggest first of all that more female students were involved in the activity of cooking and laundry than males; a phenomenon that appears to be related to social roles that are learnt and what in expected of the male and female genders. This is instructive in the sense that these respondents are young persons who are unmarried; the majority $(49.6 \%)$ was between ages 15-21. Nevertheless it appeared that the females had already been socialized to performing the activities that corresponded with their gender.

\subsection{Privacy and Social Densities}

It was not surprising that gender differences were found in responses to social densities in the hall and at the level of the bedroom because the males experienced a higher living density than the females. Gender differences were found in attitudes towards the number of persons in the hall $\left(\lambda^{2}=9.199 p \leq 0.017\right)$, satisfaction with number of people living in the hall $\left(\lambda^{2}=14.275 p \leq 0.004\right)$, satisfaction with the number living in the bedroom $\left(\lambda^{2}=11.494\right.$ $p \leq 0.014)$. More males $(42.9 \%)$ than females $(24.2 \%)$ were very dissatisfied with the number of persons in the bedroom and more males $(44.3 \%)$ than females $(16.7 \%)$ were very dissatisfied with the overall number of persons in the hall. However, in spite of the high social densities, there was no gender difference found in satisfaction with privacy in the bedroom, attitudes towards privacy in the bedroom, feelings of freedom in the bedroom, attitudes towards social densities for sharing the sanitary facilities. What was surprising was that although there were gender differences in how satisfied the respondents were with the social densities bedroom, there were no gender differences in their attitudes towards the social densities in the bedroom. What this finding suggests is that there are differences between the concepts of attitude (specifically, perception) and satisfaction and that they are not synonymous when measuring user responses to objects.

\subsection{Use of facilities}

The most significant gender differences were found in the use of certain spaces in the halls of residences. These spaces were the kitchenette and the laundry spaces provided in the residences. Gender difference were found in how often they used the kitchenette $\left(\lambda^{2}=\right.$ $52.666 p \leq 0.000)$, where else the students cooked $\left(\lambda^{2}=15.079 p \leq 0.005\right)$, how often they used the laundry $\left(\lambda^{2}=22.301 p \leq 0.000\right)$ and where else they did their laundry $\left(\lambda^{2}=16.283\right.$ $p \leq 0.004)$. Specifically, the results showed that more females $(45.5 \%)$ than males $(6.1 \%)$ often used the kitchen and they (both males and females) cooked in very different places. More (35.2\%) of the females also used the laundry often/always than the males (15.4\%) and they both used a wide variety of other places for laundry. Gender differences were also found in the students' attitudes to the kitchenette provided $\left(\lambda^{2}=27.528 p \leq 0.000\right)$; more females found the kitchen more convenient than the males. 
These results present an instructive picture of gender differences in spatial behaviour. The results suggest first of all that more female students were involved in the activity of cooking and laundry than males; a phenomenon that appears to be related to social roles that are learnt and what in expected of the male and female genders. This is instructive in the sense that these respondents are young persons who are unmarried; the majority $(49.6 \%)$ was between ages $15-21$. Nevertheless it appeared that the females had already been socialized to performing the activities that corresponded with their gender.

\subsection{Privacy and Social Densities}

It was not surprising that gender differences were found in responses to social densities in the hall and at the level of the bedroom because the males experienced a higher living density than the females. Gender differences were found in attitudes towards the number of persons in the hall $\left(\lambda^{2}=9.199 p \leq 0.017\right)$, satisfaction with number of people living in the hall $\left(\lambda^{2}=14.275 p \leq 0.004\right)$, satisfaction with the number living in the bedroom $\left(\lambda^{2}=11.494\right.$ $p \leq 0.014)$. More males $(42.9 \%)$ than females $(24.2 \%)$ were very dissatisfied with the number of persons in the bedroom and more males $(44.3 \%)$ than females $(16.7 \%)$ were very dissatisfied with the overall number of persons in the hall. However, in spite of the high social densities, there was no gender difference found in satisfaction with privacy in the bedroom, attitudes towards privacy in the bedroom, feelings of freedom in the bedroom, attitudes towards social densities for sharing the sanitary facilities. What was surprising was that although there were gender differences in how satisfied the respondents were with the social densities bedroom, there were no gender differences in their attitudes towards the social densities in the bedroom. What this finding suggests is that there are differences between the concepts of attitude (specifically, perception) and satisfaction and that they are not synonymous when measuring user responses to objects.

\subsection{Coping strategies}

The study also examined whether there were any differences in coping strategies between males and females. The coping strategies examined were both socially and physically related. There were no significant differences in the eight out of the nine coping strategies employed. Both males and females used these strategies to about similar degrees. This was surprising given the findings of previous research which suggest that males stay away from the bedroom. This study found no difference between the genders in this regard. However, there was a gender difference in demarcating personal space in the bedroom $\left(\lambda^{2}\right.$ $=20.195 p \leq 0.000$ ). More males than females employed this strategy to cope with highdensity living.

This finding supports in part previous findings (Kaya and Weber, 2003) which show that in a study of residence halls, males defined and claimed more territories for self. This was probably why they defined space for themselves in the high density situation in which they found themselves in this study. 


\subsection{Synthesis and Conclusion}

Studies which focus on attitudes to housing are not new. However, those which address gender differences in these attitudes amongst young adults are few. This study examined the differences between females and males in their responses towards their housing. Gender differences were found along three dimensions.

The first, and the most significant, was in the use of the domestic facilities namely the kitchen and the laundry. It appeared that just as gender differences have been found amongst married adults in relation to domestic issues in the house (Gifford, 1997:201), young unmarried adults had acquired gendered domestic roles and had been socialized into these roles. Indeed, there is enough evidence in the literature to suggest that gendered domestic roles are acquired early in life (Tognoli, 1987:663). Gender differences did not emerge in the use of other facilities such as the common room and the reading rooms as it did (and very strongly) in these domestic facilities.

The second most significant dimension was the social density within the halls of residence. This study has shown that males were more dissatisfied with high densities than females at all the levels at which high density was evaluated. This was not unexpected because the males lived in bedrooms of higher social densities than the females. Nevertheless, the results support findings in laboratory settings (Aiello, et al, 1983) and studies on children (Maxwell, 2003) but contradict field studies in dormitories (Aiello et al, 1981) which found that women sometimes report more crowding than men. However the field studies have not been conclusive because it has not been consistently found that females report more negative emotions towards high density (Bell et al, 2001). A reason given for this inconclusive finding is that males learn to cope by leaving the high density situation and this would mean that they would not be significant affected negatively. In this study, it was expected that the males would have adopted more coping strategies than females because they experienced a higher social density than females However, the results showed that only one strategy (out of nine) was used by males more than females; this was demarcating personal space in the room and that males did not withdraw from the situation more than females. Hence the reason why males do not report negative emotions or attitudes towards high social densities as much as females may be because the social densities are not high enough rather than the fact that they employ coping strategies such as withdrawal. In this study where the males experienced a tripling and the females, a doubling of the designed social density, the males expressed negative attitudes more than females and did not use the expected coping strategies more than females.

It is probably this experience of higher social density which accounts for why the males expressed more negative attitudes towards the hall and the bedroom and which influenced the choices which they reported that they would make in seeking new accommodation. The males disliked many more aspects of the spaces much more than the females and more of the males than females ranked the social densities as an important factor in choosing where else to live. Gender difference in satisfaction with high densities suggest an intrinsic 
difference between males and females rather than one which was learnt; especially because other studies have shown that gender differences in response to high densities may start as early as nine years of age (Aiello et al 1979).

What was surprising was that in spite of the gender differences in satisfaction with high densities, there was no difference in attitudes towards privacy, satisfaction with privacy or feeling of freedom in the bedroom. The probable reason is that one of the genders has a lower or a higher expectation of privacy than the other or employs more mechanisms to achieve privacy than the other. Studies in which the respondents are exposed to the same social density situations may explicate gender differences in privacy further.

The third and least important dimension along which there was a gender difference was the design of the hall and furniture arrangement. Both of these are design related issues. Although there is evidence in the literature to suggest that there are differences in aesthetic appreciation (Yabiku et al, 2007) between males and females as well as in their design projects (Ahrentzen and Anthony, 1993), the findings are sometimes contradictory. It appears that more research still needs to be conducted to illuminate the sparse literature in this regard.

The results also showed that gender differences appeared to be both intrinsic and as a result of socialization. The gender difference in the use of domestic spaces suggested that learned social roles assigned to males and females accounted for this while differences in satisfaction with crowding and design appeared to be intrinsic, supporting previous literature which found similar differences in children (Maxwell, 2003 and Seagert, 1982).

The implications of these results for the design and management of students residences are that first of all different designs and arrangements need to be made for males and females to accommodate their domestic behavioural differences. More cooking and laundry spaces would be needed in female halls than in male halls. Secondly, students housing may not be assumed to be gender neutral facilities. The facilities need to respond to gender differences which this research has found and which future research may find.

\section{References}

Ahrentzen, S. and Anthony, K. H. (1993). Sex, stars and studio: A look at gendered educational practices in Architecture. Journal of Architectural Education. 47, (1), 11-29

Aiello, J. R., Nicosia, G. J., and Thompson, D. E. (1979). Physiological, social and behavioural consequences of crowding on children and adolescents. Child Development, 50, 195-202.

Aiello, J. R., Thompson, D. E., and Brodzinsky, D. M. (1983). How funny is crowding anyway? Effects of room size and the introduction of humor. Basic and Applied Social Psychology, 4. 193-207

Bell, P.A., Greene, C. T., Fisher, J. D., and Baum, A., (2001). Environmental Psychology. Harcourt College Publishers NY. 
Amole, D., / Asian Journal of Environmen-Behaviour Studies, ajE-Bs, 2(3) Apr./Jun. 2017 (p.1-12)

Dolapo Amole (1999). Evaluative Dimensions of Students Residential Facilities. Ife Psychologia Vol 7 № 2 pp 4568

Dolapo Amole. (2009). Residential Satisfaction in students housing Journal of Environmental Psychology 29, 7685. (UK)

Giddens, A. (2001) Sociology. Blackwell publishers. Oxford, UK

Harrison, A. A., Stuthers, N. J., and Putz, B. J. (1991). Mission, destination, mission duration, gender and student perceptions of space habitat acceptability. Environment and Behavior 23, (2) 221-232

Kakad, K. (2000). Gender, Culture, and Architecture in Ahmedabad and Berlin. Gender Technology and Development 2000; 4; 201-223

Kaya, N., and Weber, M. J. (2003). Territorial behavior in residence halls: A cross-cultural study. Environment and Behavior, 35 (3), 400-414.

Keeley, R. M. and Edney, J. J. (1983). Model house designs for privacy, security and social interaction. Journal of Social Psychology. 119, 219-228

Lawton, C. A., Charlseton, S. I. and Zieles, A. S. (1996). Individual and gender related differences in indoor way finding. Environment and Behavior. 26, (2). 204-209.

Pain, R. (2001). Gender, race, age and fear in the city. Urban Studies 38 (5\&6) 899-913

Peatross, F. D., and Hansell, M. J. (1992). Changing lives/changing spaces: An investigation between gender orientation and behaviors and spatial preferences in residential kitchens. Journal of Architectural and Planning Research, 9, 239-257

Seargert, S. (1982). Environment and children's mental health: Residential density and low income children. In A. Baum and J. E. Singer (eds) Handbook of Psychology and Health, 2, 247-271. Hillsdale NJ. Lawrence Erlbaum

Shrestha, G. (2000). Gender Relations and Housing: A Cross-community Analysis. Gender Technology and Development 2000; 4; 61-86

Stamps III A. E. and Nasar, J. L., (1997). Design review and public preferences: effects of Geographical location, public consensus, sensation seeking, and architectural styles. Journal of Environmental Psychology (1997) 17, $11-32$

Tognoli, J. (1987). Residential environments. In D. Stokols \& I. Altman (Eds.), Handbook of Environmental Psychology (Vols. 1 \& 2, pp. 571-691). New York: John Willey.

Walden T. A., nelson, P. A., and Smith, D. E., (1981). Crowding, privacy and coping. Environment and Behavior, 13, 295-224

Yabiku, S. T., Casagrande, D. G., and Farley-Metzger, E. (2007). Preferences for landscape choice in a southwestern desert city. Environment and Behaviour, 40 (3), 282-400. 